\title{
SURGICAL ANATOMY OF THE VEINS OF THE LOWER LIMB - A CADAVERIC STUDY
}

\author{
Salgado $S^{1}$, Abeysuriya $V^{1}$, Pathirana $A^{2}$ \\ ${ }^{1}$ Department of Clinical Anatomy, Faculty of Medicine, Ragama, Sri Lanka. \\ ${ }^{2}$ Department of Surgery, Faculty of Medicine, University of Sri Jayawardenapura, Sri Lanka.
}

\begin{abstract}
Introduction: With the advent of new surgical techniques, an adequate knowledge of precise anatomy of the venous system of the lower limb is important for safe surgery. The aim of this study is to provide some basic information for those who are interested in phlebology.
\end{abstract}

Materials and methods: The anatomy of the superficial and deep veins of both lower limbs was studied in 20 human cadavers (age 42-72 years) of both sexes (12 males: 08 females). Great saphenous vein (GSV) and small saphenous vein (SSV) were traced from medial and lateral malleoli to the sapheno-femoral junction (SFJ) and saphenopopliteal junction (SPJ) respectively. The number of deep perforators was counted and measurements were taken from a fixed anatomical land mark.

Results: In both lower limbs of 17 cadavers (85\%), the course of GSV was similar to the course described in the commonly used text books. Large tributary with a diameter similar to GSV at the SFJ was seen in 3 cadavers (15\%). The point of entry of SSV into the popliteal vein varied greatly. In majority of cadavers the opening was at the level of the popliteal skin crease and in others it was either above or below this. Large deep perforators were found in the calf and thigh with irregularly distributed small perforators.

Conclusion: A majority of individuals have the lower limb superficial venous pattern described in standard text books. However, a significant minority had variations, which could have important implications on the presentation and treatment of varicose veins.

Sujatha Salgado MBBS, M.Phil

Senior Lecturer, Department of Clinical Anatomy,

Faculty of Medicine,

Ragama,

University of Kelaniya,

Sri Lanka.

Vasitha Abeysuriya MBBS

Lecturer, Department of Clinical Anatomy,

Faculty of Medicine,

Ragama,

University of Kelaniya,

Sri Lanka.

\author{
Aloka Pathirana MBBS, MS, FRCS (Eng) \\ Consultant Surgeon, \\ Department of Surgery, \\ Faculty of Medical Sciences, \\ University of Sri Jayawardenapura, Sri Lanka. \\ Corresponding author \\ V. Abeysuriya \\ Lecturer, Department of Clinical Anatomy, \\ Faculty of Medicine, Ragama, \\ University of Kelaniya, Sri Lanka. \\ vasitha76@hotmail.com \\ Tel: 94-1-77-3528167
}




\section{Introduction}

In the recent past, scientific studies on the functional anatomy of the lower extremity venous system have been sparse. With the advent of new surgical techniques, such as superficial endoscopic perforator surgery, venous anatomy of lower limb gained distinguished attention. As the precise knowledge of the venous anatomy is important we describe the anatomy of the superficial and perforating veins of the lower limb based on our observations on several dissections.

\section{Materials and methods}

Both lower limbs of twenty human cadavers of both sexes ( 8 females, 12 males) with a mean age of 48 years (range of $42-72$ years) were dissected to study the anatomical architecture of the superficial and perforating veins of the lower limb. The course of great saphenous vein (GSV) was traced from the medial malleolus to the sapheno-femoral junction (SFJ) and small saphenous vein (SSV) was traced from the lateral malleolus to the saphenopopliteal junction (SPJ) in both legs. The number of deep perforators was counted and the distance from fixed anatomical landmarks such as medial malleolus, lateral malleolus and medial epicondyle, to the deep perforators were measured.

\section{Results}

The GSV ascends about one finger breadth anterior to the medial malleolus and crosse the medial surface of the tibia obliquely, passes posterior to the medial condyles of the tibia and femur and ascends along the medial side of the thigh and pierces the cribriform fascia at the saphenous opening ending in the femoral vein. In 17 cadavers (85\%) the course of the GSV in both lower limbs was similar to the course described in commonly used text books $(1,2)$.

Although the course of GSV was the same, a large tributary having a similar diameter at the SFJ accompanied the GSV in 3 cadavers (15\%).

The point of entry of SSV in to the popliteal vein varied greatly. In 12 cadavers (60\%) the point of entry was at the level of the popliteal skin crease.
In 5 cadavers (25\%) the opening was below and in 2 cadavers it was above the level of skin crease. Small saphenous vein draining into GSV giving a minute tributary to the popliteal vein was found in one cadaver (5\%).

Two to three large deep perforators in calf, 1-3 large deep perforators in the thigh and irregularly distributed small perforators both in the calf and the thigh were seen in each limb.

The position of the below knee perforators were measured from the medial malleolus. Of the 40 limbs, the below knee deep perforators were found in the following manner.

The deep perforators were found at the medial malleolus in 36 limbs (90\%), 5-9 cm from the malleolus in 8 limbs (20\%), 10-14 cm in 16 limbs (40\%), 15-19 cm in 12 limbs (30\%), 20-24 cm in 28 limbs (70\%), 25-29 cm in 16 limbs (40\%) and $30-35 \mathrm{~cm}$ in 24 limbs (60\%).

The above knee perforators were measured from medial epicondyle. In 20 limbs (50\%) perforator was found at 6-8 $\mathrm{cm}$ from the medial epicondyle and in $24 \mathrm{limbs}(60 \%)$ at $10-13 \mathrm{~cm}$ and in $28 \mathrm{limbs}$ (70\%) at $14-17 \mathrm{~cm}$.

\section{Discussion}

The GSV follows the same course as described in text books in $85 \%$ of cases, and in $15 \%$ of cases there was a parallel large tributary which accompanied the GSV on its anterior aspect in the thigh, which is compatible with the accessory saphenous vein described in text books $(1,2)$.

The deep perforators which were found as below knee perforators from the medial malleolus at 5-9 $\mathrm{cm}, 10-14 \mathrm{~cm}, 20-24 \mathrm{~cm}$ are compatible with the Cockett I, Cockett II, Cokett III and ' $24 \mathrm{~cm}$ perforator' described in available literature $(3,4)$. The perforator at $15-19 \mathrm{~cm}$ in $30 \%$ of cases was not described in available literature.

Although some of the authors have studied the sites of the perforators, no measurements have been taken for the above knee perforators. The incom- 
petent thigh perforating veins may occur anywhere in the thigh, from the upper edge of the patella to a few centimetres below the saphenofemoral junction. The majority are found in the middle third of the thigh.

The above knee perforators described in our study may be the Dodd's perforators described in literature (5).

\section{Conclusion}

Knowledge of precise anatomy of superficial lower limb veins is important since the presentation and treatment of varicose veins may vary depending on the anatomical distribution.

\section{References}

1. Snell RS. Clinical anatomy, 7th edition. Lippincott Williams \&Wilkins. 2003; 614: 662.

2. Sinnatamby C. Last's Anatomy Regional and Applied.11th Edition. Churchill Livingstone, Elsivier 2006; 117-8.

3. Moore KL, Dalley AF. Clinically Oriented Anatomy, 5th Edition. Lippincott Williams \& Wilkins 2006; 580.

4. Mozes G, Gloviczki P. Surgical anatomy for endoscopic subfascial division of perforating veins. J Vasc Surg 1996; 24: 800-8.

5. Dodd H, Cockett EB. The pathology and surgery of the veins of the lower limb. Londres, Churchill Livingstone, 1976. 